\title{
ARTÍCULOS
}

\section{EL HURTO EN LAS ALMADRABAS DEL SUR DE EUROPA: ENTRE LA RECIPROCIDAD NEGATIVA, LA REIVINDICACIÓN POLÍTICA Y LA ECONOMÍA MORAL}

\author{
POACHING IN THE TRAPS OF SOUTHERN EUROPE: BETWEEN NEGATIVE \\ RECIPROCITY, POLITICAL CLAIM AND MORAL ECONOMY
}

\author{
David Florido-del-Corral ${ }^{1}$ \\ Departamento de Antropología Social, Universidad de Sevilla
}

Ambra Zambernardi²

Departamento de Cultura, Política y Sociedad, Universidad de Torino

Recibido: 6 de octubre de 2019; Aprobado: 1 de junio de 2020.

Cómo citar este artículo / Citation: Florido-del-Corral, David y Ambra Zambernardi. 2021. "El hurto en las almadrabas del Sur de Europa: entre la reciprocidad negativa, la reivindicación política y la economía moral". Disparidades. Revista de Antropología 76(2): e025. doi: <https://doi.org/10.3989/dra.2021.025>.

RESUMEN: La economía almadrabera en el sur del Mediterráneo ha basculado históricamente entre diversos principios organizativos complementarios: reciprocidad, redistribución y mercado, pero siempre en el marco institucional de un sistema de relaciones comerciales de amplio alcance. Aprovechando apuntes etnohistóricos referidos a las almadrabas del Estrecho de Gibraltar (Andalucía, España) y de las islas de Cerdeña y Sicilia, los autores interpretan las prácticas de hurto y aprovechamiento de atún y otras especies por parte de los trabajadores en el marco de culturas laborales, que se entienden mejor si se entienden desde conceptos como reciprocidad negativa, economía moral o derechos consuetudinarios de aprovechamiento comunitario de bienes que pasan de un estado de naturaleza a otro de apropiación social.

PALABRAS CLAVE: Almadrabas; Reciprocidad negativa; Economía moral; Mediterráneo.

ABSTRACT: The economy of the tuna traps [almadrabas] in the southern Mediterranean has historically been based on various complementary organisational principles: reciprocity, redistribution and the market, but always within the institutional framework of a wide-ranging system of trade relations. Taking into account ethno-historical notes referring to the traps in the Strait of Gibraltar (Andalusia, Spain) and the islands of Sardinia and Sicily, the authors interpret the practices of theft and exploitation of tuna and other species by workers in the framework of labour cultures, which are better understood from concepts such as negative reciprocity, moral economy or customary rights of community use of goods that pass from a state of nature to one of social appropriation.

1 Correo electrónico: dflorido@us.es. ORCID iD: <https://orcid.org/0000-0003-1908-5756.>.

2 Correo electrónico: ambra.zambernardi@unito.it. ORCID iD: <https://orcid.org/0000-0002-7915-2458>. 


\section{INTRODUCCIÓN: MARCO TEÓRICO Y PERSPECTIVA DE ANÁLISIS}

En este texto pretendemos dar a conocer prácticas sociales de gran perdurabilidad histórica en un espacio geo-cultural definido, el de las almadrabas del sur de España e Italia, aprovechando el trabajo etnográfico de sus autores ${ }^{3}$. En una primera parte, exponemos los conceptos desde los que analizar las prácticas sociales, que tanto históricamente como aún en la actualidad, siguen sosteniendo el robo de pescado en estos contextos culturales. En un segundo momento, exponemos tales prácticas, y los valores y percepciones asociados a ellas, recogiendo noticias históricas que nos permiten plantear una secuencia multisecular. Diferenciamos los ámbitos meridionales de Italia (particularmente Cerdeña) y España (golfo de Cádiz), sin embargo, podremos concluir que la continuidad temporal y la extensión geográfica de tales hábitos expresan profundas conexiones entre las culturas del trabajo de las almadrabas del contexto mediterráneo.

Nuestro marco teórico usa la reinterpretación de la teoría del intercambio y la noción de reciprocidad negativa (Thomas 1991; Lomnitz 2005), la economía moral y la reclamación de justicia en la redistribución de bienes (Scott 2000) y, finalmente, el debate acerca de la propiedad de bienes demaniales como son las poblaciones de peces (Bensaïd 2007). A partir de la noción original de Sahlins (1963), en la que subyace un planteamiento políticamente igualitarista en las relaciones de intercambio, la reciprocidad negativa se ha definido por la ausencia de un compromiso de equilibrio, pues se trata de obtener más por menos -a partir de diversas estratagemas, entre las que caben el uso de la fuerza, el engaño, el robo, el saqueo-, una especie de "toma y daca» (Gouldner 1960), lo que sitúa a esta esfera de intercambio en los márgenes sociales, entre extraños. Más que encastrada en un entorno socio-simbólico dado, la relación

3 David Florido tiene distintos trabajos sobre las almabrabas atlánticas andaluzas, especialmente las próximas al Estrecho de Gibraltar (Conil de la Frontera, Barbate, Zahara y Tarifa en Cádiz); Ambra Zambernardi ha realizado su tesis doctoral obre las almadrabas del Mediterráneo, con trabajo de campo en Cerdeña y Andalucía, sobre todo, bajo la dirección de Paola Sacchi (Universidad de Torino) y David Florido (Universidad de Sevilla) (Zambernardi 2020). parece situada en un contexto asocial, en el sentido apuntado por Weiner (1996): el intercambio de reciprocidad negativa tendería a liquidar la relación social duradera. Esto supuso, en términos teóricos, dejar al modelo de intercambio de reciprocidad negativa en una suerte de limbo, lo que ha supuesto su escaso desarrollo. Como subraya Lomnitz (2005: 320), el problema subyacente a estos planteamientos es que se establece un vínculo autoevidente entre solidaridad-reciprocidad-igualdad en las sociedades "primitivas» (de "pequeña escala», según Lomnitz), cuando la revisión de la teoría del intercambio, a partir de los ochenta, ya ha puesto de manifiesto conexiones entre formas de intercambio que bajo el discurso de reciprocidad se producen al mismo tiempo que asimetrías y desigualdades; o que en ese tipo de sociedades también es posible constatar la existencia de lo que la Antropología Económica ha definido como intercambio de mercado, basado en relaciones impersonales o con una orientación de obtener alguna ganancia en la relación. No podemos suponer que la reciprocidad es interdependiente necesariamente con la solidaridad entre individuos («los amigos hacen regalos»-«los regalos hacen amigos»), lo que evitaría formas de dominación en las sociedades donde predomina el don. Para este autor, debe hablarse de dos formas de reciprocidad negativa, la simétrica -entre actores $o$ nodos autónomos que interactúan en pie de igualdad-, y la asimétrica -entre agencias entre las que median relaciones de dominación- (Lomnitz 2005: 321).

En esta tradición analítica, la perspectiva es siempre estructural: son los marcos sociales los que definen el tipo y los contenidos de las relaciones, dejando al margen las prácticas y modos subjetivos de percepción de las relaciones. Moreno Feliú (2002), sin embargo, ensaya una aproximación microsociológica a partir del estudio de caso de las relaciones de intercambio al interior de campo de exterminio de Auschwitz. Ella plantea que las relaciones sociales mediante las que se generan los intercambios se producen entre dos polos, uno (moralmente) positivo y otro (moralmente) negativo, en relación con lo que los actores en juego consideran lícito y lo que no. Las relaciones se pueden analizar de modo típico-ideal entre los valores antagónicos tomar-dar // pedir-recibir// guardar-ser. Cuando predomina el 
primer término de los pares (tomar-pedir-guardar) la relación oscila hasta el polo de reciprocidad negativa, y viceversa. Es el contexto social en el que tienen lugar los intercambios el que hace que relumbre una u otra dimensión. Podríamos decir que la reciprocidad negativa, más que un espacio estructural de relaciones de intercambio (en el margen de la tribu, entre estados, entre extraños, entre empresa y trabajadores), es una lógica que los actores ponen en juego ante determinadas circunstancias en virtud de un orden moral.

En una obra más reciente de la misma antropóloga (Moreno Feliú 2011), se desarrollan las posibilidades analíticas de esta aproximación, realmente novedosas y fructíferas, al entender que la reciprocidad negativa, como actitud de reclamar, está presente en distintos marcos institucionales: en la reciprocidad generalizada de las sociedades de cazadores-recolectores, o en la reciprocidad redistributiva de los imperios antiguos o del sistema feudal europeo, que se amoldan al concepto de reciprocidad negativa asimétrica de Lomnitz. Así como está presente en los sistemas de justicia vindicativa (Terradas 2008) en el que partes del cuerpo humano, o la propia vida, entran en un sistema de equivalencias a través del cual se dirimen conflictos y pagos políticos dentro de o entre grupos humanos (Graeber 2012)4. Aproximando el debate hacia nuestro objeto de estudio, en las sociedades desigualitarias, la reciprocidad negativa puede ser el sustrato normativo sobre el que se levantan prácticas como rapiñas, robos y levantamientos cuando los actores entienden que el orden moral justo ha sido transgredido, siendo así que puede instrumentar las rebeliones campesinas pre-modernas europeas, tal y como las entendió Hobsbawm $(1978,1983), 0$ como también ha sido estudiado en el ámbito andino (Orlove 1990; Gascón 1999-2000). Este será el ámbito teórico de nuestro estudio: las prácticas de robo como un elemento de las culturas del trabajo (Palenzuela 1995:13; Florido 2017: 121) de las almadrabas meridionales mediterráneas. En estas culturas del trabajo, además, podemos aplicar el concepto de hidden transcript -discurso oculto- de J.C Scott (1999,

4 Es lo que D. Graeber (2002) denomina «economías humanas», en el sentido de que el sistema de equivalencias y los intercambios a los que da lugar se usaban, para crear, responder, gestionar o destruir lazos humanos, un espacio privilegiado para conocer los orígenes de la moneda en los sistemas económicos primitivos.
2000, 2013), una conjunción de actos de lenguaje y prácticas de los grupos subalternos para expresar tanto formas de resistencia como estrategias para mantenerse y obtener provecho -de las que también participan los poderosos-, sin oponerse abiertamente a la estructura desigualitaria de la que forman parte unos y otros (Rachjenberg 2015: 51).

El fenómeno tiene una vertiente jurídica que ha generado un sustancioso debate a raíz de los escritos de un joven Marx, periodista en la Gaceta Renana (Marx 2007), que usaba su pluma para oponerse a la deriva mercantilista y de reforzamiento del poder del Estado Prusiano en Renania para anular el derecho consuetudinario mediante el que campesinos progresivamente empobrecidos aprovechaban despojos de campos y bosques, como la leña caída $a^{5}$. Los campesinos y braceros pretendían reproducir en el tiempo formas consuetudinarias de un híbrido régimen de propiedad, de origen feudal, que permitía complementar sus economías de subsistencia mediante derechos como el de pasturaje para el ganado, espigar y rebuscar en tierras de labor, recolectar leña caída o cazar determinados animales en los bosques y campos (Bensaïd 2007:109). Marx refiere aquí una noción de propiedad muy aprovechable para las prácticas que vamos a elucidar en relación con las reclamaciones y robos de pescado en los entornos almadraneros. A saber, la propiedad como un haz de relaciones sociales, de fuerza y de representaciones ideológicas en disputa, como el caso de la apropiación de leña caída ponía de manifiesto. Frente al derecho «natural» a la supervivencia bajo el principio de urgencia vital de los campesinos, se situaba el de propietarios rurales en un contexto de mercantilización de la leña de gran importancia socio-económica debido a la diversidad de usos a mediados del siglo XIX-. Según Marx, la leña caída era una «limosna» de las fuerzas elementales de la naturaleza, más "humanitaria» que la propia humanidad (entiéndase, los ricos propietarios) (2007: 38-39). Para Di Lucia, se trata de una aportación sustanciosa del pensador de Tréveris:

5 Los propietarios rurales logran que la cámara renana defina como robo la apropiación de leña no sólo cortada del árbol, o la ya transformada, sino la que, accidentalmente, ha caído y ya no pertenece al árbol y, consiguientemente, según Marx, no puede ser objeto de derecho de propiedad y sí de los derechos de uso consuetudinarios que garantizaban un auxilio económico de subsistencia a los campesinos. 
los objetos de naturaleza contingente o accidental (la leña desprendida del árbol, o los túnidos en nuestro caso) prefiguran las reglas por las que la sociedad debe tratarlos: en este caso, debería prevalecer el aprovechamiento comunal sobre la propiedad exclusiva, o una hibridación de ambas (Di Lucia 2010: 136) ${ }^{6}$. Según Marx estas formas de apropiación colectiva consuetudinarias demuestran un «sentido jurídico instintivo» (Marx 2007: 39) mediante el que los campesinos «necesitan satisfacer un impulso de justicia» (2007: 38) -obsérvese la relación con la noción de reciprocidad negativa mantenida. Y culmina con una reflexión que bien podemos aplicar a nuestro caso de estudio, el robo de pescado:

«En la recolección, la clase elemental de la sociedad humana se enfrenta, ordenándolos, a los productos del poder natural elemental. Algo similar ocurre con los productos que crecen salvajes formando un accidente puramente casual de la propiedad y que por su poca importancia no se constituyen en objeto de la actividad del auténtico propietario; algo similar ocurre con la rebusca, el espigueo y derechos consuetudinarios de ese tipo». (Marx 2007: 39)

Es por ello que no estamos hablando sólo de economía, sino de concepciones y relaciones jurídicas culturalmente informadas. En definitiva, nos situamos ante un derecho social que se opone al interés privado (Terradas 2008: 21), que sólo puede entenderse al ponerse en relación con un orden moral ${ }^{7}$. El caso del

6 Di Lucia denomina a esta posición «materialismo eidológico", que es caracterizado porque el legislador no puede crear una ley sobre un objeto, sino que la norma viene ya determinada por la naturaleza del mismo. En el caso de la leña muerta es su carácter contingente, accidental, el que permitiría su apropiación comunal por los campesinos en situación de urgencia económica. Así se constituyó desde el derecho germano medieval un modo consuetudinario de relación con ese tipo de objetos (aplicable también a otros objetos silvestres o a las espigas tomadas después de la recolección), que cumplieron una importante función económica en las estrategias de campesinos, hasta que el derecho civil moderno impuso sobre todas esas relaciones el derecho de propiedad excluyente, afianzando el empobrecimiento de los desposeídos (Di Lucia 2010:134).

7 En esta misma obra podemos encontrar un marco social que nos ayuda a entender la naturaleza socio-jurídica, y aún económica, de las prácticas de robo o hurto de pescado en los sitios almadraberos, cuando Terradas explica que la respuesta judicial al robo puede tener más robo de pescado bien puede situarse en ese espacio interseccional, escurridizo, en el que el discurso oculto de resistencia se mantiene silente, pero es visible, como la caza furtiva, el robo de ganado o la leña en el monte que ya no es comunal (Rachjenberg 2015: 52). Para Scott, al referir las prácticas de caza furtiva entre aldeanos, "la disidencia ideológica se expresa casi siempre a través de prácticas dirigidas a renegociar discretamente las relaciones de poder» (Scott 2000: 225). Se trataba de "entrar en posesión real de lo que les negaba la ley» (2000: 224) a través de una práctica de apropiación callada, -«la voz plebeya es muda», refiere Scott-, mediante la que el inferior intenta acomodarse circunstancialmente a relaciones de dominación.

Los almadraberos gaditanos (Andalucía) y de Carloforte (Cerdeña) no sólo hablan a través de este tipo de prácticas de un orden moral, sino que tienen un discurso instituido, impregnado de valores. Lo que planteamos es que no se trata de válvulas de escape, sino de responder, a baja intensidad y con vocación de perdurabilidad, a la situación de dominación con "ciertas formas de conducta y resistencia» (Scott 2000: 226), mostrando una evidente intención política ${ }^{8}$.

\section{APUNTES ETNOHISTÓRICOS: EL ROBO DE ATUNES Y LA DISTRIBUCIÓN DE CAPTURAS ACCESORIAS Y DE «DESPOJOS» DEL ATÚN DESDE EL ANTIGUO RÉGIMEN A LA MODERNIZACIÓN.}

Cuando usamos de modo genérico el término «robo» de atunes, nos estamos refiriendo a distintas

relación con regular las ofensas entre personas o con garantizar los medios de subsistencia de determinados grupos sociales que con la defensa de la propiedad privada (Terradas 2008: 904).

8 Scott enumera, según qué colectivos, las siguientes prácticas más comunes: entre población esclava (se supone que en EE.UU. en los siglos XVIII-XIX): robos y sisas, ignorancia fingida, absentismo, despreocupación dolosa, venta clandestina, sabotajes; entre población campesina (en los sistemas feudales): caza furtiva, ocupación de fincas, recolección ilegal de ganado y otros elementos del bosque, desmonte clandestino, falta de pago de tributos. Encontramos aquí fuertes resonancias de los planteamientos de E. P. Thompson (1975) acerca de las prácticas de resistencia de campesinos y silvicultores ingleses en los siglos XVIII-XIX, frente a las modificaciones legislativas que se imponen de la mano de las transformaciones en las relaciones de producción y de propiedad en esa misma época. 
prácticas en el universo almadrabero: por un lado, la sisa de atunes rojos enteros (la menos frecuente); por otro, de acuerdo con normas consuetudinarias, a la adquisición de las denominadas capturas accesorias, especies que no son atunes -en particular el denominado en Andalucía pescado menudo-, pero que caían en las redes de la almadraba y debían ser distribuidos entre el personal ${ }^{9} ; \mathrm{y}$, por último, nos referimos a los denominados "despojos» del atún (trozos del despiece que no se comercializaban en los grandes circuitos, procedente de la cabeza, el espinazo, las vísceras, huevas...) y que se distribuían entre la marinería. Mientras que la sisa de atunes estaba perseguida, el resto de las prácticas era controlada y se acomodaba al sistema de retribuciones consuetudinario, siendo la que mejor se adapta al marco teórico elucidado en el anterior apartado ${ }^{10}$.

Se puede entender la historia social de la almadraba en Andalucía como una evolución desde una economía de prestigio -almadrabas de tiro o vista- a una economía de mercado -almadrabas fijas- (Florido 2006). En un nivel macro, la almadraba que irrumpió en el bajo medievo se basaba en una economía señorial atravesada por principios redistributivos bajo el lenguaje de la reciprocidad, en la que el monarca concedía, de modo exclusivo, el aprovechamiento de las pesquerías de atunes y de la sal a epígonos aristocráticos que previamente habían desempeñado funciones militares y defensivas en la zona litoral. Grandes casas como el ducado de Medina Sidonia, o el de Arcos, en el mediodía peninsular, compitieron entre sí por esta concesión, hasta que la primera de las familias consiguió un imperfecto monopolio. En el nivel micro social, los duques organizaban la pesquería haciendo uso de la lógica señorial de prestigio: conseguían materias primas, servicios y trabajo a cambio de garantizar la defensa de una frontera amenazada y otorgar

9 Melvas, bonitos, sardas, voladores...

10 El profesor Ignasi Terradas -a quien no termina de convencer el uso de la expresión reciprocidad negativa para este tipo de prácticas-, en comunicación personal a propósito de un borrador de este texto, nos indicó que esta práctica de retribución no es infrecuente: "hay bastantes ocupaciones tradicionales en las que la remuneración o retribución del trabajo se cobra también en parte con la especie desaprovechada o sobrante del producto mercantil, e incluso se da luego a vecinos o amigos: lo he visto en fábricas textiles, en minas de sal y de carbón, en fábricas de jabón, de perfumes, en carpinterías, herrerías...». retribuciones en dinero y especie (pan y carne) a la compleja trama de posiciones laborales, muy jerárquica (Santos 2017). Y no debe olvidarse que el destino de la producción era un comercio de largo alcance. Es decir, siguiendo a Gudeman (2001) ${ }^{11}$, hemos de entender que las lógicas económicas no se desarrollan de modo uniforme ni homogéneo, ni en las transiciones históricas se produce la sustitución de un modo por otro. Se trata más bien de prácticas que reflejan distintas lógicas, que generan un sistema híbrido de relaciones económicas, políticas y jurídicas. Así, mientras que el destino de las producciones en el comercio del atún se manejaba desde una racionalidad puramente lucrativa, la organización de la pesquería sólo era entendible a través de una serie de contraprestaciones, algunas graciosas, en las que se amalgamaban regalos (el duque entregaba atunes a comunidades religiosas $y$ a la localidad, por ejemplo, al inicio de la temporada, así como se comportaba con prodigalidad en la corte con el atún como producto de lujo) y obligaciones de unos sobre otros, debiendo cumplirse determinadas reglas morales en las retribuciones. En el nivel local, no responder a esta gramática social podía suponer la aparición de reclamaciones y de robos.

Los robos de atunes disfrutaron de una importante tradición en las almadrabas andaluzas meridionales (Antón Solé 1965; Herrera 1974 y 1981; GuillaumeAlonso 1988). Soto Melgar (2015) apela al ingenio literario de un poeta menor de la Sevilla del Seiscientos, Félix Pertio Bertiso, quien publicó en 1654 un romance en pliego de cordel para narrar las aventuras de un antihéroe reclutado en Sevilla con el objeto de llevar a cabo el hurto sistemático de atunes de los lugares almadraberos. El segundo de los romances está específicamente dedicado a describir las estratagemas para el robo de atunes, o de sus partes más valiosas, para poder venderlos en el mercado a espaldas del duque (Soto Melgar 2015:

11 Gudeman define dos dimensiones («realms») en la economía, el ámbito de relaciones «comunitarias» y el ámbito de relaciones "mercantiles», en toda sociedad y todo tiempo (Gudeman 2001:10), bajo una importante variedad de patrones institucionales que sólo el trabajo etnográfico puede deslindar. Mientras que la lógica comunitaria se orienta a garantizar la reproducción de los lazos comunes, autosustentarse como una totalidad social, la de mercado se basa en relaciones contractuales guiadas por el auto-interés, para la búsqueda un beneficio cuantificable, independientemente de sus conexiones sociales. 
336), hurtos que habrían de ser llevados a cabo por el personal de «cuerda» (ventureros), población patibularia que era objeto de levas en Sevilla para realizar las actividades de fuerza sin especialización técnica (Figura 1). Es decir, se trataba de población sin implicación social ni moral en el sistema de relaciones de la densa trama de contraprestaciones en los lugares almadraberos. Este aspecto es trascendental para comprender la práctica del hurto, según el modelo teórico presentado, pues los ventureros ni pertenecían al dominio señorial ni sentían vínculo ni obligación respecto a los dueños de las almadrabas. En Álvarez de Toledo (2007: 33) se describen, entre las competencias del capitán de la almadraba, el control de robos de atunes, de su subasta clandestina, del robo de ganado y su intervención por posibles altercados a partir de las chanzas y los juegos de azar. $Y$ sus ayudantes de a caballo, entre otras funciones, deben guardar los atunes en tierra y vigilar su conducción hasta la chanca (edificio en el que son procesados) (Santos 2017).
Con los primeros ensayos de la almadraba fija, de buche, en Zahara de los Atunes (Cádiz), en 1807, que corre a cargo de personal valenciano, el administrador reconoce en carta dirigida al duque que esta marinería ha estado más pendiente de "coger despojos y robar» que de su trabajo (Santos 2017: 52, n.30), prácticas que parecen formar parte de la cultura laboral de estos pescadores y que quedarán arraigadas definitivamente cuando se asiente la almadraba fija en la costa gaditana, desde el último tercio del siglo XIX. Robar y tomar los despojos era una práctica que subsistía desde el sistema tradicional de almadrabas de tiro o vista, en la que los trabajadores recibían,

"Además de los sueldos y menestras, diversas "gratificaciones": a los atalayas se dieron 45 atunes y otros 53 se repartieron entre los distintos gremios, desde los oficiales a los "ventureros", dándose también las cabezas y espinetas a los trabajadores». (Santos 2017: 49, n.18)

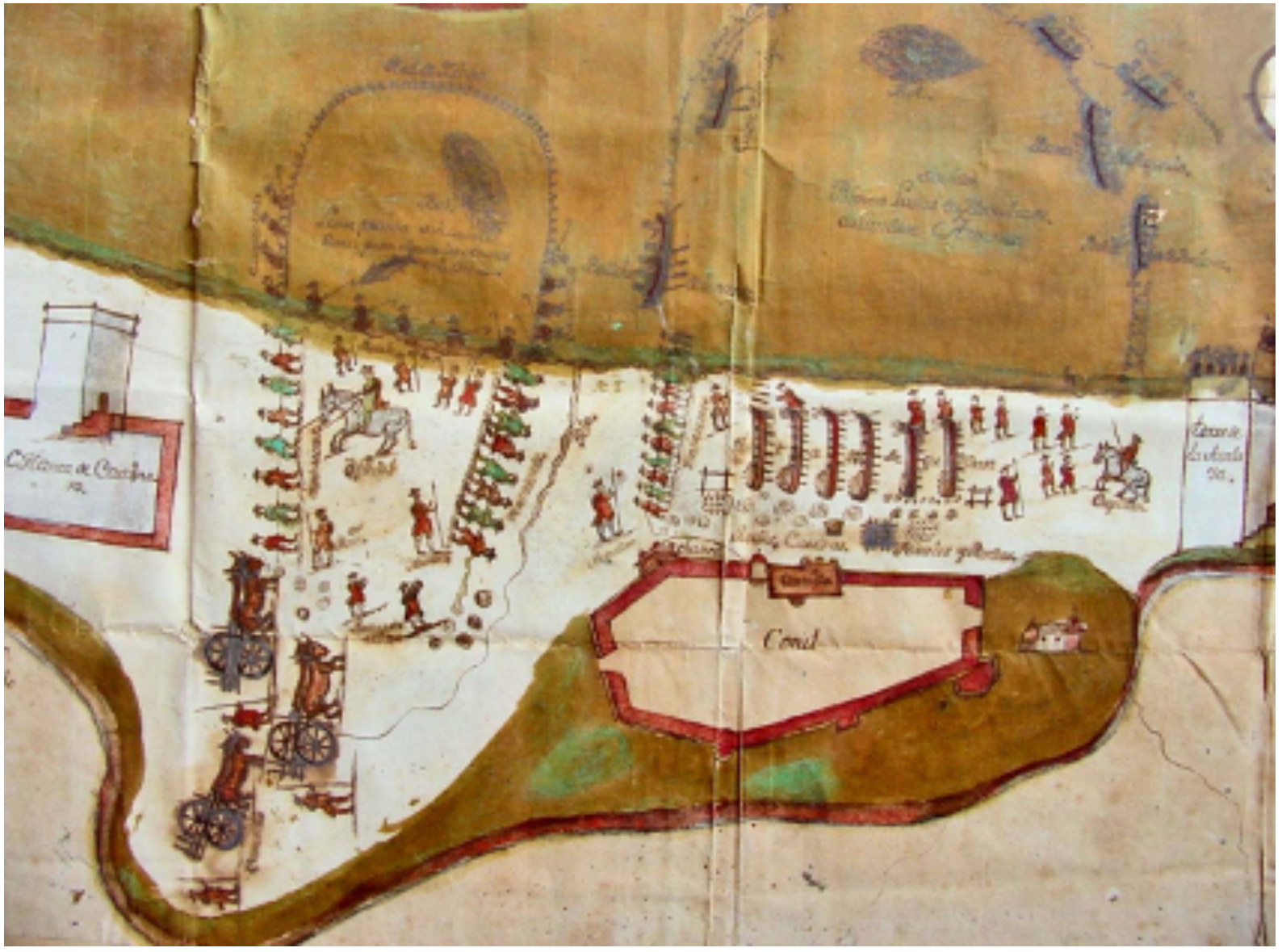

FigurA 1. - Plano de la almadraba de Conil, 1768. Archivo Ducal de Medina Sidonia. 
Lo que evidencia prácticas de regalías en especie, que serán una constante en la almadraba a partir de entonces y en los dos siglos posteriores ${ }^{12}$.

Antonio Santos recupera un documento de la casa ducal de 1808 en el que se reconoce la ardua tarea del capitán y sus subordinados para evitar el robo de atunes de un extraordinario y tardío lance, "en una noche oscura y acometidos por todos lados, por numeroso concurso, armados de cloques para conseguir sus dañados fines» (Santos 2017: 53). Hay un trasfondo de economía moral, reciprocidad negativa y reivindicación política según la perspectiva apuntada en todo este paisaje. Siendo los atunes un don de la naturaleza, el privilegio monopolista de ser capturado en las almadrabas del duque (o de cualquier otra casa armadora) será siempre objeto de reclamación por parte de quienes se esfuerzan mediante su trabajo en su captura. De hecho, han existido siempre reclamaciones respecto a la propiedad de los atunes que no eran capturados en almadrabas. La casa ducal los reclamaba para sí en virtud del privilegio otorgado por la Corona, revocado en 1814 , pero pescadores y vecinos entendían que un atún capturado fuera de la almadraba, aún en territorio marino frente a las tierras señoriales, no estaba sujeto a privilegio, sino que era un don apropiable por cualquiera, como documenta ya a finales del quinientos el historiador Agustín de Horozco (2000: 112). Sobre estos peces no debía regir ningún sistema de propiedad privativa, según los pescadores que arponeaban a los que morían desorientados en los caños y corrales de la costa, como tampoco debía aplicarse el privilegio a los peces de la almadraba que no eran atunes, y que consuetudinariamente se han considerado para disfrute de la tripulación. Podemos hilar estas consideraciones del carácter comunal de los bienes marinos no sujetos a privilegio con el hecho de que en territorios levantinos y meridionales, según testimonia Antonio Sáñez Reguart a finales del siglo XVIII, el arte de jábega se denominaba "arte real» o "de malla real»"13. Ello quiere decir que los

12 En términos generales, la retribución de los almadraberos combinaba la entrega de una paga, bien fija, bien "a partes» (en función de la producción lograda), que se completaba con raciones diarias y/o semanales de harina y carne.

13 «Este distintivo según costumbre de nuestros pescadores, pende de que los Arraeces ó Patrones de Xábega no pueden impedir á persona alguna que eche una mano á tirar de la red para sacarla del mar, propietarios de barcas y artes no podían negarse a repartir una parte del pescado capturado a aquellos que se acercaban a las faenas de recogida de la red en la playa, aun no formando parte de la tripulación. Esta práctica ha sido documentada etnográficamente por Eva Cote (2015: 21) en las costas de Málaga para el siglo $\mathrm{XX}$, y la hemos podido corroborar directamente en la última de las jábegas que se cala en el Mediterráneo andaluz. Es decir, prevalece una reminiscencia de que, al menos para determinadas especies y en determinadas pesquerías, se hibridan derechos de uso colectivos y derechos privativos. Nuestra hipótesis es que estas resonancias indican el mantenimiento de una percepción socialmente instituida según la cual el mar es un ecosistema que, si no está sujeto a privilegio restrictivo mediante concesión de monopolio (un concepto jurídico que se acercaría a la noción de propiedad privativa excluyente), podía ser disfrutado de acuerdo a sus propias normas o reclamado por los hechos, por los vecinos. Se produce, como reseñábamos a propósito de la lectura de Marx, una asociación entre naturaleza, derecho natural y derechos de uso de campesinos, aquí pescadores. Si nos detenemos en este punto es para hacer entender cuán factible es, sobre el fondo de esta tradición etnohistórica, la pervivencia de prácticas entendibles desde las categorías de economía moral, reciprocidad negativa y «discurso oculto" de Scott a las que hemos hecho referencia.

La información histórica que disponemos sobre el decisivo tránsito de las almadrabas entre los siglos XIX y XX, en el sentido de modernización, apuntala esta línea de análisis. En el caso de la economía del atún, en la documentación de principios del siglo XIX se prefigura el panorama socio-laboral que será predominante hasta finales del siglo XX: entre otras cosas, disputas sobre los despojos y repartos de distintas partes del atún que se distribuían según normas consuetudinarias, además de la soldada y los robos de atunes, que sí estaban especialmente perseguidos. A partir de la eliminación de los privilegios señoriales en las actividades de pesca (1814), se instituye una compañía de pesca en Conil

\footnotetext{
la cual por esta fatiga o trabajo se hace acreedora a la pesca que salga en el lance por dos tercios de parte, asi como los que embarcan para calarla, tienen parte entera». El Comisario de Marina duda si la denominación real hace referencia a esta circunstancia o a que se trata de una «red privilegiada á toda otra pesquera» (Sáñez Reguart 1791, 5: 352).
} 
(1815) -que agrupaba a los armadores, patrones y pescadores residentes entre Vejer y San Fernando (Cádiz)-. Esta entidad pretende mantener el sistema de tiro, a base de jabegones (jábegas de gran tamaño) para la pesca de túnidos y aprueba un reglamento de almadrabas (1817), en el que se reconoce el reparto de despojos del atún entre el personal, así como penas para evitar prácticas como el maltrato del personal por los capitanes o los hurtos de pescado entre los trabajadores. Por su parte, la casa ducal apostó por el sistema de pesca de buche, más eficiente, basado en jornales a marineros foráneos y en una mayor inversión en equipamientos. Es decir, frente a una racionalidad modernizadora, los pescadores asociados proponen un modelo de economía social, organizado mediante la distribución de la ganancia a partes y gratificaciones (Santos 2017: 53 y ss.), que encaja mejor con la inercia histórica en las culturas del trabajo de lógica redistributiva de carácter comunitario, bajo una noción demanial de los bienes pesqueros y bajo los principios de una economía sustentada en principios morales. Esta pugna se disolverá a partir de los años sesenta del ochocientos, con un nuevo reglamento de almadrabas (1866), que instaurará el buche o armamento fijo en todo el litoral, con un régimen de administración «moderno» (Santos 2017: 64); es decir, sobre principios de eficiencia económica y utilidad, tanto para los empresarios como para las arcas del estado.

¿Qué información tenemos en el sur de Italia? Documentalmente no es tan rica, pero las fuentes históricas disponibles sí atestiguan prácticas que acabamos de mencionar en Andalucía. «El que no sabe robar no va al atún» es un dicho que la tradición literaria siciliana viene repitiendo desde el siglo XVIII, a partir de la referencia del marqués de Villabianca (1986 [1774]). El padre jesuita Cetti, naturalista, también afirma a finales del setecientos que la práctica del robo en las almadrabas de Cerdeña estaba plenamente institucionalizada: se trataba de no ser sorprendido en un acto que era arropado por un discurso de legitimidad, lo que podemos leer, de nuevo, como un indicio del "discurso oculto» de Scott y como manifestación de reciprocidad negativa, en tanto que se trata de un derecho a reclamar, así percibido y practicado por los trabajadores, lo que se considera dispensado por la naturaleza. Tales prácticas eran definidas como un modo de justicia reivindicativa que los trabajadores lograban mediante su praxis en el mar, una reclamación por la vía de los hechos de un principio de equidad, que no debe definirse como hurto, y que tiene su nombre específico: la busca (rebusca), término español (Cetti 1778), que en el ámbito campesino se ha usado históricamente para referirse al derecho de recolección de frutos caídos que se consideraban donados por la naturaleza, bajo el permiso (por acción u omisión) de la propiedad o sujeto a formas consuetudinarias de aprovechamiento. Podríamos diferenciar los hurtos de los despojos. Según D’Amico (1816: 157), a lo largo del siglo XIX los hurtos constituyen una parte de la redistribución para trabajadores y técnicos; mientras que Pavesi (1889: 193-194) atestigua la referencia a los términos busca (Cerdeña) o procaccio (Sicilia) para referirse a la capacidad de los trabajadores de hacerse con partes de atún para compensar de este modo sus exiguas pagas.

El significado del despiece del atún como un modo de retribución en el marco de una economía moral es algo que podemos reconstruir a partir del caso de las almadrabas gaditanas, en el decisivo tránsito de industrialización del atún en las primeras décadas del siglo XX. Distintos testimonios evidencian cómo la práctica del robo era congruente con la percepción del azar y la aleatoriedad con la que el océano se mostraba pródigo a los trabajadores. La puerta franca era la señal de apertura del régimen de control de las trabajadoras de las fábricas de atún, cuando el pescado a laborar era excesivo. Significaba que podían entrar y salir sin ser rastreadas por las palpadoras, cuya misión era, precisamente, evitar los robos cotidianos del género que se trabajaba en las instalaciones ${ }^{14}$.

Las primeras décadas del siglo XX se caracterizaron por un proceso de concentración empresarial una recuperación del sistema monopolista del Antiguo Régimen bajo un nuevo formato- en todo el arco suratlántico, que condujo a la instauración del Consorcio Nacional Almadrabero (CNA) (19281971) (Florido 2013), una corporación de capital estatal y de los grandes empresarios almadraberoconserveros que se habían asentado entre Huelva y

14 La práctica de hurto y sisa de la producción atunera se mantuvo y se expandió en los centros fabriles. Las palpadoras tenían la misión de evitar que las estibadoras de pescado de las fábricas se llevasen una parte del producto a sus casas, mientras que un vigilante hacía lo propio sobre los ronqueadores (personal masculino dedicado a despiezar los atunes). 
Cádiz en ese período (Ríos 2005). Uno de los temas que más polémica suscitó fue la cuestión de las retribuciones, en particular el sistema de reparto de despojos y regalías. En el parlamento nacional fueron denunciadas las difíciles condiciones laborales (salarios, horarios, infraestructuras de vivienda, alimentación, etc.) así como prácticas como «la supresión del regalo de carne de atún, la prohibición de despojos, la dificultad para que el atún, fresco o en conserva estuviese a disposición de la población local» (Florido 2017: 78). El no reconocimiento de estas instituciones tradicionales, unido a las duras condiciones de trabajo, provocó huelgas de los operarios de almadraba en las provincias de Cádiz y Huelva, en los años treinta.

Esta década constituye un momento liminal muy apropiado para comprobar la vigencia de planteamientos comunalistas respecto al modo de explotación del atún rojo en las almadrabas meridionales ibéricas. Una serie de escritos en el periódico local La Independencia de Barbate (publicado entre 1929 y 1930) sacaron a la superficie el discurso crítico contra el Consorcio Nacional Almadrabero, reclamando la restitución del «antiguo derecho de los pueblos a aprovecharse de los beneficios de las Almadrabas» ${ }^{15}$. ¿A qué se refería el editor con ese antiguo derecho de los pueblos? Se trata de viejos usos, como "comer pescado cuando lo cogen"; "cuando hay poco pescado, entregar a los trabajadores los desperdicios»; y, si la levantada era buena, se les permitía aprovecharse «de otra clase de atún mejor», lo que les estimulaba para trabajar sin descanso, hasta asegurar todo el atún que había dentro de la almadraba ${ }^{16}$, en unas jornadas laborales que podían ser de doce, catorce o más horas, ininterrumpidamente. En otro número de esta misma publicación se denuncia que se ha abandonado la costumbre de repartir algo del producto a todos los que colaboraban en el transporte del atún cuando las levantadas eran copiosas $^{17}$-como ya se ha referido que se ha realizado históricamente en las jábegas andaluzas. Especialmente enojoso era para los barbateños el espectáculo de la destrucción (por incineración o arrojándolos al mar) de los despojos de

15 La Independencia de Barbate, 11, noviembre de 1929:8

16 "Recuerdos de un almadrabero viejo», artículo firmado por José Sánchez, presidente del Pósito Barbate, en La Independencia de Barbate, 20, 1930.

17 La Independencia de Barbate, 19, 1930 los atunes, sin que pudiesen ser aprovechados por los trabajadores. Así, el presidente del Pósito Pescador de Barbate culminaba una carta al gerente del Consorcio, Serafín Romeu, con la siguiente exhortación:

«Yo os pido, Señor Conde, que prohíba a toda costa que al pie de este monumento que construimos a la memoria de vuestro padre ${ }^{18}$, usted con su dinero y nosotros con nuestro esfuerzo, se cometa la ignominia de quemar ante los hambrientos ojos de los barbateños pobres, lo que siempre se sacó fuera para que lo aprovechara el que lo necesitara». ( $L a$ Independencia de Barbate, 21, 1931)

Es muy esclarecedor comparar estas consideraciones con la exposición de motivos del Real Decreto de 20 de marzo de 1928 que instauraba el Consorcio Nacional Almadrabero, que expresaba nítidamente la racionalidad de la empresa capitalista auspiciada por el estado. Por eso las reclamaciones se elevaban en particular contra Serafín Romeu i Fages, conde de Barbate, que había entregado la almadraba a la eficiencia industrialista, cuando su padre-Serafín Romeu i Portas- había comprendido bien la lógica preexistente. De ahí que el mismo José Sánchez describiera una levantá, en 1905 y con Romeu i Portas como concesionario del pesquero, con más de tres mil atunes, que pudieron aprovecharse gracias a la colaboración de los faluchos de todo el pueblo en las operaciones de pesca y traslado de los atunes. En justa compensación por ello, recibieron su parte de atún. José Sánchez quiso resumir la ética de Romeu i Portas -la de una época- en las siguientes palabras del empresario: "ya que se han cogido, hay que aprovecharlos, cuando Dios da, da para todos, ya sabéis lo que os digo ${ }^{19}$. No hay por qué insistir en la relación de esta afirmación con los conceptos de suerte, azar y providencia, propios del comunalismo de la lógica pre-productivista, a los que haremos referencia más adelante.

En Barbate ya no se comía atún al fresco, pues "hasta los despojos que en tiempos del Sr. Romeu se entregaban a los trabajadores para que aprovechasen la parte comestible adherida a la cabeza, espinazo,

18 Se debe referir a la Chanca, la fábrica de manifactura del pescado, o al chalet, vivienda particular de los Romeu en Barbate, a continuación de ésta.

19 «Una levantada en la perla del océano». La independencia de Barbate, 1930, 19: 2. 
etc., se arroja hoy en alta mar» ${ }^{20}$. El socialista Eladio Fernández Egocheaga, a la sazón presidente de la Federación de Pósitos de Andalucía Occidental, elevó un escrito al ministro de Marina, que se publicó en distintos diarios españoles, solicitando la revocación del Consorcio Nacional Almadrabero. Entre otras consideraciones (Florido 2017:78), el líder obrerista denunciaba:

"Que se ha suprimido el regalo de carne de atún a todos los obreros empleados, según era costumbre; que se ha suprimido el regalo de atún de calderada por una exigua cantidad en metálico; que se prohíbe el aprovechamiento de residuos, de espinas y cabezas, cuando la abundancia no permite convertirlas en abonos, llegando, incluso a rociar con gasolina los residuos para que nadie pueda aprovecharlos; que una gran parte del personal no está matriculado, y, en fin, que es tal el cúmulo de defectos y abusos, que se han convertido las almadrabas en verdaderos cotos cerrados». («Informe de las actividades del Consorcio dirigido al Sr. Ministro de Marina», en España Marítima y Pesquera, junio de 1930)

Estas reclamaciones se entienden mejor a la luz de las consideraciones sobre economía moral y la concepción de un derecho social que se opone a la defensa del interés privado a partir de la lectura de Terradas, de Bensaïd y su interpretación de los textos tempranos de Marx. Llegaron al ámbito ministerial, a raíz de la labor de portavoces locales, como el mencionado José Sánchez, almadrabero, presidente del Pósito de Pescadores de Barbate, que se refería al gerente del Consorcio Nacional Almadrabero, Señor Romeu, como «dueño absoluto del mar, cuando V.E. sabe que las almadrabas fueron en otras épocas y volverán a serlo cuando los pueblos dispongan de medios, bienes comunales de éstos que se han usurpado a los pescadores en el transcurso de los tiempos» ${ }^{21}$.

\section{EL MANTENIMIENTO DE LAS PRÁCTICAS DE ROBO Y APROVECHAMIENTO DE LOS DESPOJOS DURANTE LA INDUSTRIALIZACIÓN.}

Todos estos relatos reflejan una idealización de las relaciones sociolaborales que vuelven a

20 La Independencia de Barbate, 8, 1930: 10.

21 La Independencia de Barbate, 16, 1930: 2. aparecer en las entrevistas de almadraberos de más edad quienes, sin menospreciar la dureza del trabajo ni la dificultad de las condiciones laborales, rememoran la "alegría» que para "el trabajador» suponía la almadraba. "iQué almadraba más buena para el pobre!», recordaba emocionado un capitán al relatar su socialización temprana en los poblados almadraberos. En una época general de carestía, en la posguerra, el almadrabero mantiene en la memoria la disponibilidad de bienes, tanto en la pesca (a través de capturas accesorias o de despojos de atún) (Figuras 2 y 3) como en la logística de los bastimentos en los poblados almadraberos, cuando los operarios podían afanarse -hurtar- distintos tipos de género alimenticio (higos, garbanzos, arroz...), en una manifestación de reciprocidad negativa, por la vía de los hechos.

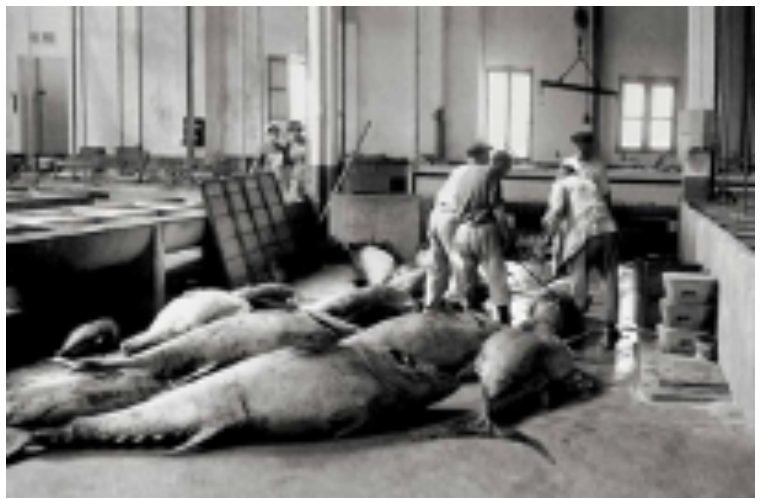

FIGURA 2. - Fábrica de atunes de Barbate, años setenta del siglo XX. Se aprecia el trabajo de los almadraberos en la cara de los peces para aprovechar algunos de sus despojos. Autor: desconocido. Incluida en la Publicación Imágenes Tradicionales de la Pesca, III Muestra, Barbate. Consejería de Agricultura y Pesca, 2010: 30.

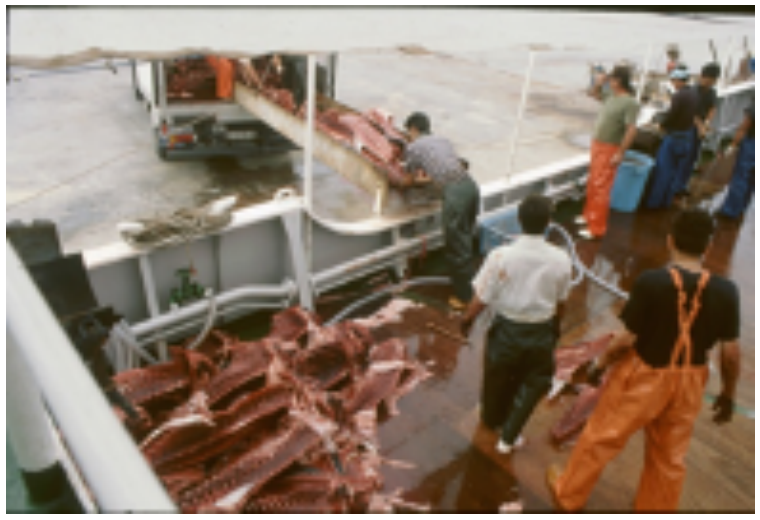

FIGURA 3.- Los espinazos de los atunes son trasladados a fábricas conserveras locales. Autor: Juan Ruiz. 
Hemos de entender estas prácticas en el marco de la institución de la harampa ${ }^{22}$ y su lógica redistributiva (ver Cuadro 1): distribución de pescado (en especie o/y en metálico) entre los trabajadores como reconocimiento a su trabajo, por hacer participado en las comunes operaciones de pesca y que el armador reconoce como un signo del compromiso recíproco que lo une a los trabajadores. La sisa de las capturas accesorias, por tanto, se percibe como harampa tomada por propia cuenta, legitimada por el esfuerzo realizado, con lo que el robo de estas especies era una práctica bien encuadrada en una economía moral de la que participaban desde el empresario a los trabajadores, pasando por los capitanes:

«En aquel momento no repercutía en ningún daño a la empresa porque si había atún, el pescado pequeño no se echaba de ver, y después además es un poco un premio a la persona, que entonces más que ahora las redes no resistían, y había que tirarse al agua por fuerza y estarse en el agua dos horas cogiendo pescado, arrastrando atunes, eso era poco a lo mejor lo que estaba cogiendo, si se llevaba un bonito, como si se llevaba dos, lo único que podía hacer [el capitán] era mirar para otro lado y no verlo, no es que se estuviera a lo mejor robando. Yo he visto a mi padre otras veces que a pesar de que se hubiera llevado uno incluso le decía: "cógelo, cógelo ése para ti", y en vez de uno se llevaba dos o tres. ¿Por qué?, porque se lo estaba ganando, era una forma de premiar el trabajo que estaba haciendo, que no se lo iban a ver en la oficina luego, ni se lo iban repercutir por horas». (A.C., capitán de almadrabas, Isla Cristina)

Pero la práctica del robo puede entenderse a la luz de otros valores, también injertados en las culturales laborales, en relación con el azar, la aleatoriedad y

22 La harampa (jarampa) es una regalía que recibe el marinero en los sistemas de redistribución «a la parte» (es decir, retribución no mediante jornal, sino en función de las capturas, por productividad, adaptando el lenguaje), por el mero hecho de salir a faenar y participar en la jornada de trabajo. Es una garantía de retribución de un mínimo, aun cuando no se capture pescado. Se puede recibir en especie o en metálico (con la modernización de las relaciones laborales). En el caso de las almadrabas, la harampa estaba constituida por capturas accesorias: voladores, escualos, túnidos menores. el sentido de la reclamación justa en determinadas condiciones. Cuando se produce una desafección entre los trabajadores y los mandos respecto de la empresa, al considerarse que las condiciones de trabajo son injustas ante un bien que dona la naturaleza, el pescador está en condiciones de romper las reglas -aunque sea bajo control social, conociendo las formas permitidas de romperlas- para aprovechar mejor la aleatoriedad, muy presente en los discursos hegemónicos de la cultura pesquera, y entrar en una esfera de vértigo y ausencia de control: algo así como jugársela. Los trabajadores se sienten atraídos por el valor, no solamente pecuniario, de la competencia -una suerte de lucha agonística entre iguales- por capturar lo que pródigamente, y por azar, el mar concede; perciben el valor de retar a la autoridad que representa la capitanía y los administradores. El siguiente apunte etnográfico, de una almadraba gaditana, nos ayuda a comprender este principio: había venido a admirar las faenas de almadraba un mando de la Guardia Civil y se temía por los marineros que fuese recompensado con un bonito de buen tamaño, una captura accesoria que debía pertenecer a la tripulación. El hurto de la pieza, con el riesgo añadido de hacerse delante de la representación de la autoridad, más allá de la empresa, adquirió más valor:

«[Los leperos] todo lo que podían arrebañar en la mar, en el cuadro, bonitos, caballas, lo escondían, para luego venderlo [...] Fíjate si es fino un lepero que quitó un bonito enmallado en la red clara del copo, un bonito grande, y aquel día iba para ver la levantá el capitán de la Guardia Civil, [...] y dice el segundo [capitán]: "cógelo y ponlo ahí en la proa", de la sacada [embarcación], lo cogió y lo puso en la proa de la sacada. Mira, cómo se dio arte un lepero, era acopejador [función de llevar los atunes y capturas del arte a las embarcaciones], vino, se embarcó en la sacada, se llevó el bonito y nadie se dio cuenta, el segundo dice: "¿y el bonito?", el bonito..., [...] y el segundo decía: "si yo supiera quién ha sido le daba la cuenta" [lo despedía]». (A.G, almadrabero, El Rompido, Carataya)

Estamos ante algunos de los significados que González Alcantud (1993) reconoce en los juegos de azar -a partir de la teorización de R. Caillois (1997 [1967]) y de distintos referentes etnográficos 


\begin{tabular}{|c|c|c|}
\hline Tipo de retribución & Descripción & Lógica económica \\
\hline Jornal, salario & $\begin{array}{l}\text { Retribución de carácter fijo en metálico, } \\
\text { sujeta a revisiones del convenio laboral } \\
\text { y con pluses aplicados a las distintas } \\
\text { tareas desempeñadas en función de la } \\
\text { productividad (ver siguiente fila). } \\
\text { Cerdeña: Esta paga es un jornal diario. }\end{array}$ & $\begin{array}{l}\text { Mercado. } \\
\text { Los capitanes buscan favorecer a los } \\
\text { marineros mediante empleo de horas } \\
\text { extraordinarias, mejor remuneradas, } \\
\text { jugando con las vicisitudes del } \\
\text { calamento del arte. }\end{array}$ \\
\hline $\begin{array}{l}\text { Regalías por pieza } \\
\text { capturada (incentivos), } \\
\text { plus de capturas. }\end{array}$ & $\begin{array}{l}\text { Retribuciones en metálico o en especie, } \\
\text { en relación con la productividad, recogidas } \\
\text { en convenio (por segmentos de } 500 \\
\text { atunes), pero también sujetas a iniciativas } \\
\text { discrecionales del capitán para estimular el } \\
\text { trabajo. } \\
\text { Antes y durante el CNA era habitual el } \\
\text { reparto de despojos. Desde los años } \\
\text { noventa, se ha incorporado el regalo de } \\
\text { atún, a propuesta del capitán. } \\
\text { Copejeadores, buzos y marineros que se } \\
\text { tiran al agua reciben un plus por pieza } \\
\text { capturada (no en el caso de Cerdeña). } \\
\text { Son especialmente importantes (Andalucía) } \\
\text { la distribución del «pescado chico/ } \\
\text { menudo»: melvas, bonitos o sardas, } \\
\text { voladores. }\end{array}$ & $\begin{array}{l}\text { Redistribución, relaciones personales } \\
\text { en un entramado jerárquico. } \\
\text { El capitán calibra cuándo usarlas en } \\
\text { función de la marcha de la temporada, } \\
\text { y de si tiene información si se han } \\
\text { cubierto gastos de la empresa. } \\
\text { La lógica económica doméstica articula } \\
\text { los objetivos y prácticas de marineros } \\
\text { en el acceso a capturas accesorias de } \\
\text { «pescado chico/menudo». }\end{array}$ \\
\hline $\begin{array}{l}\text { Harampa (percances) y } \\
\text { «robar pescado» }\end{array}$ & $\begin{array}{l}\text { Aportación al trabajador por participar } \\
\text { en las operaciones de pesca, que en las } \\
\text { almadrabas se materializa en el reparto de } \\
\text { capturas accesorias (de escualos, jureles, } \\
\text { besugos, sargos, pargos, caballas y otras } \\
\text { especies), en metálico y en especie. } \\
\text { Un modo particular de esta retribución es } \\
\text { la sisa o robo de «pescado chico/ menudo» } \\
\text { con el conocimiento del capitán. } \\
\text { En Cerdeña los actos de robo se centraban } \\
\text { en piezas y despojos de atunes, también con } \\
\text { el consentimiento del capitán. }\end{array}$ & $\begin{array}{l}\text { Predominantemente doméstica. } \\
\text { Se considera que es un derecho de } \\
\text { «la gente»/trabajadores, para su } \\
\text { economía doméstica, y se reparte o } \\
\text { bien en especie o bien metálico, tras la } \\
\text { venta de las capturas. } \\
\text { La práctica del robo se podría } \\
\text { considerar como una forma de } \\
\text { reciprocidad negativa, pues surge de } \\
\text { la reclamación de los trabajadores por } \\
\text { su colaboración en la empresa, y de la } \\
\text { conciencia del derecho de percepción } \\
\text { de lo que dona el mar, aunque no esté } \\
\text { contemplada contractualmente. }\end{array}$ \\
\hline Otras aportaciones & $\begin{array}{l}\text { Ropa de trabajo, vivienda (con suministros), } \\
\text { para los trabajadores foráneos. } \\
\text { Cerdeña: La empresa aporta un fondo en } \\
\text { efectivo para financiar las comidas que los } \\
\text { almadraberos cocinan cada día en el real. }\end{array}$ & Redistribución. \\
\hline
\end{tabular}

CUADRo 1. - Síntesis de los sistemas de retribución en las almadrabas (siglo XX). Fuente: Elaboración propia 
entre los que se incluye la pesca de almadraba-: el azar (alea), el carácter agonístico (agon), el de la representación teatral (mimicry) y el ilinx o ruptura de la norma, valores que son corroborados por nuestras etnografías. Se produce en un contexto competitivo, ante la mirada de superiores que deberían evitarlo pero que sólo actúan en caso de superarse ciertos límites que se consideran no permisibles, justo en un punto en el que, todavía, algunos trabajadores intentarán desafiar la restricción. Además, es una forma de responder a la aleatoriedad que permite a los trabajadores tener la sensación de ver reconocido su derecho como partícipes del aprovechamiento de lo que legítimamente consideran apropiable. En estas condiciones, participan con fruición en el juego, un tanto dramático, de sortear la vigilancia, de desafiar al control, de demostrar sus habilidades. Los capitanes, haciendo la vista gorda, también corroboran el drama. En la lógica de este juego, las prácticas de hurto, tanto las históricas como las actuales, son tratadas como un "secreto a voces», un "secreto de Pulcinela» en lengua partenopea, es decir, lo que todo el mundo sabe o intuye, porque el personaje dramático de Polichinela se encargaba de airear con ironía.

Cuando la práctica de robo del pescado menudo era cuantitativamente importante, porque las capturas de estas especies lo eran (millares de piezas), los capitanes se veían obligados a copejearlas (trasladar las capturas a las embarcaciones) en su barco, la sacada, donde hay una cubierta que impide esconderlas. El papel del capitán había de guardar un impreciso equilibrio más o menos flexible con los acaparamientos impropios de los trabajadores, los que traspasan el límite, en el juego de simulaciones en el que se produce esa forma de reciprocidad negativa que es el acaparamiento, hasta que decide que «ya no se coge más pescado porque el copejeador se distrae» (Figura 4).

Un aspecto fundamental para participar en los robos es saber hacerlos. Para ello se requiere cierta experiencia en la almadraba, conocer las tácticas, las relaciones implícitas entre el capitán y los trabajadores, los silencios de aquel y el límite a partir del cual ya se iniciaba la algarada por el exceso:

«No, no, eso lo tienes que hacer bien, no se puede abusar porque si te pasas y te cogen te echan y no puedes reclamar en ningún lado ¿por qué? Porque eres un ladrón. Y los ladrones no tienen justicia en ningún lado.

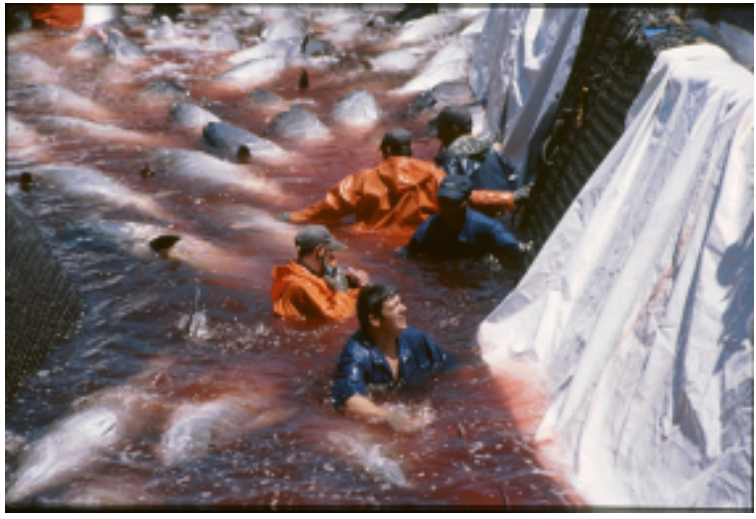

FIGURA 4. - Un copejeador se introduce una sarda en la ropa de agua durante las faenas de copejeo. Autor: Juan Ruiz.

Una melvita, dos melvitas, pues sí. Te lo tienes que hacer bien». (J., almadrabero copejeador, Isla Cristina)

Durante distintos momentos del siglo XX, tanto en el Consorcio Nacional Almadrabero, como a partir de los años ochenta, las casas armadoras han intentado monetarizar la harampa; y estandarizar, con un número igual para todos los marineros, la entrega de sardas, el pescado más valorado entre las capturas accesorias. Pero estos intentos fracasaron. Podríamos decir que la lógica de reciprocidad negativa quería ser sustituida por la redistributiva, por parte de las empresas, en un contexto plenamente mercantil. Así que valores como el desafío del orden social y el sentido agonístico entre los trabajadores terminan triunfando. A los marineros no les interesaba sólo el valor crematístico de las piezas a repartir, sino también el valor socio-simbólico de retar a la autoridad, de reclamar mediante hechos lo que consideraban legítimamente como apropiable, con derecho de ser reclamado, un género que, sólo después, ellos convierten en dinero mediante la venta.

En las almadrabas meridionales italianas, también se ha documentado a lo largo del siglo XX el papel de guardianes -al igual que las palpadoras en las fábricas españolas- con la misión de registrar las ropas y enseres de los trabajadores (Conte 1985: 63 y 72). Los términos vantaggio y percacci (ventaja y percance) se consideraban, en las almadrabas sicilianas de Trapani, derechos de técnicos y trabajadores, como reconocimiento a su trabajo, y se estipulaban, o bien en pedazos de atún o en sus despojos (Lentini 1986: 44), y algunos testimonios han dado el nombre 
de «pezzi di camorra» ${ }^{23}$ a estos aprovechamientos (Rubino 1994: 110). Para los trabajadores, «non è un furto, ma un esproprio proletario» [no es un robo, sino una expropiación proletaria]. En las salomas -cantos marineros para ayudarse rítmicamente en las faenas más duras de remo y leva de las redes- de la costa occidental Siciliana, se hacía referencia a que primero se captura el atún y se desembarca en tierra y a continuación se lleva a cabo el robo para comer ${ }^{24}$, práctica legitimada por las difíciles condiciones de trabajo y la iniquidad de las recompensas obtenidas (Sarà 1998: 98). Se trata de prácticas que también estaban presentes en las almadrabas africanas, tanto en Marruecos (Florido 2017), como en Libia (Ravazza 2005 y 2007). Paralelamente, según las condiciones empresariales, se han mantenido con más o menos intensidad las prácticas de aprovechamiento de despojos, dado que no ha dejado de formar parte de las culturas laborales (Florido 2017).

\section{QUÉ QUEDA DEL ROBO EN EL NUEVO MARCO DE ECOLOGÍA POLÍTICA}

Las prácticas y significados de las culturas del trabajo entre los almadraberos en relación con principios como reclamar lo que legítimamente se consideraba «de la gente», sobre valores de igualdad, azar y contingencia, o el desafío a la autoridad bajo formas más o menos ritualizadas de robo, todo ello, empieza a desaparecer desde la última crisis importante en el ciclo socio-ecológico de atún rojo en el Mediterráneo, que se profundiza con el nuevo siglo. El Plan de Recuperación del Atún Rojo ${ }^{25}$, en vigor desde 2008 a instancias de la organización ICCAT -Comisión Internacional para la Conservación del Atún Atlántico-, ha supuesto un nuevo marco de ecología política del atún, basado en un sistema de

23 "Piezas de camorra», entendiendo por camorra fraude, abuso de fuerza, derecho arbitrario. Por tanto, el uso de este término ya refleja un sentido político en estas prácticas, en el sentido de la línea interpretativa propuesta por Scott o Thompson, y en sentido de reciprocidad negativa que venimos manteniendo.

24 «'nta sta tunnara cc'è n'usanza... ogni mattina si fa mattanza... prima i pigghiamu, n'terra i purtamu... poi li sgugghiamu... e ppi manciari s'avi arrubbari».

25 Reglamento (CE) 1559/2007, del Consejo, de 17 de diciembre de 2007, por el que se establece un Plan de recuperación plurianual para el atún rojo del Atlántico Oriental y el Mediterráneo. topes de capturas y reparto en cuotas por estado y empresa, en el que tanto las flotas pequeñas como los trabajadores de las almadrabas han salido perdiendo (Florido 2014b). Las retribuciones ligadas a la productividad, en especie o en metálico, han ido perdiendo importancia en los últimos años, hasta casi desaparecer, por mor del sistema de cuotas que son asignadas desde la Comisión Europea de Pesca a cada estado miembro, que a su vez las distribuye entre las distintas pesquerías. Las regalías según la cantidad de capturas devienen en un imposible, pues cada almadraba tiene un tope de capturas que se alcanza con facilidad dentro del mes y medio de pesca en que está operativa una almadraba en la actualidad. Asimismo, la apropiación del pescado chico es cada vez más difícil, ya sea como regalía estipulada, ya como robo. El tope de captura por cada almadraba y las nuevas condiciones de producción a demanda del atún obligan a operaciones de sangrado: liberar del copo los atunes que no se van a vender en cada jornada extractiva. Es decir, cada operación de pesca consiste en extraer de cada almadraba un número acordado de antemano con los comercializadores, siempre contingentes reducidos. Con una racionalidad económica centrada exclusivamente en suministrar atún rojo al fresco y ultracongelado a circuitos económicos cada vez más amplios, han desaparecido las jornadas en las que, aun no habiendo atunes, sí había capturas accesorias.

«El pescao chico se ha perdido. Después de que hay poco, al no hacer levantás de atún no se hacen levantás de pescao chico. Y se sangra todos los días, y el pescao chico no se aguanta con el atún. $Y$ antes se cogía todo mixturado, atunes, melvas, sardas, todo el pescao chico. Esos días que se cogía atunes y pescao chico se hartaban [de cogerlos los almadraberos], porque ¿yo, capitán, iba a echarle cuenta al pescao chico habiendo atunes? El que cogía más cogía más, si tú ganabas cuatro o cinco mil pesetas con el pescao chico pues las ganabas». (RF, Capitán de almadraba, Isla Cristina)

En Cerdeña (Carloforte y Portoscuro) también el nuevo marco de ecología política del atún rojo ha tenido efectos decisivos sobre las culturas del trabajo. Desde 2011, los atunes capturados en las almadrabas son trasladados a jaulas de engorde, de modo que las formas de aprovechamiento de las vísceras y piezas menos comerciales, que tradicionalmente se habían 
repartido entre la tripulación, han desaparecido. Antes, en el discurso local, el atún era del mar, que pródigamente lo ponía a disposición del hombre, pasando a ser del propietario cuando llegaba a tierra y empezaba a ser laborado, lo que justificaba el aprovechamiento que la tripulación hacía con sus despojos: trozos de atún, vísceras, corazón, huevas... Ahora, por el contrario, el atún completo pertenece a la empresa desde el momento en que es capturado y así será vendido en los nuevos mercados al fresco (y ultracongelado) en circuitos internacionales. El hecho de que en el convenio laboral vigente se estipule que la empresa debe satisfacer una módica cantidad de dinero por cada atún trasladado para repartir entre los trabajadores (0,50€/atún) lo podemos considerar el testigo material de que se reconoce a los marineros lo que han reclamado tradicionalmente mediante la práctica, de reciprocidad negativa bajo el marco de economía moral, del despojo de los atunes.

Persiste, de todos modos, el reparto de huevas, mojama y otras vísceras entre los marineros, aquellas partes que no se aprovechan por la empresa propietaria de la almadraba, en la única levantada a la antigua usanza que se sigue realizando. El atún capturado en esa mattanza es procesado en la fábrica local, pero los despojos de los atunes enmallados (es decir, los que quedan atrapados en las redes, y no son matados al levar redes) se siguen repartiendo como percance entre los tonnarotti. Esta distribución se realiza por el capitán al final de la campaña, como un medio de recompensa que tiene en cuenta los méritos y esfuerzos de cada quien a lo largo de la temporada. El capitán, como en el caso español, debe saber salvaguardar los intereses de la empresa, pero, equilibradamente, apoyar, defender y proteger a su tripulación, siempre que ésta lo respalde con su trabajo.

Como en Andalucía, existe insatisfacción de los trabajadores con el nuevo sistema extractivo. Exclaman: "ora ci manca il sangue! " [inos falta la sangre!], para expresar su disconformidad, y en este contexto pueden reaparecer de nuevo los robos, con el sentido, aún fortalecido de "discurso oculto» de Scott, de reivindicación material, y reconocimiento a un tiempo, de su posición de debilidad.

\section{REFLEXIONES FINALES}

En las páginas precedentes, hemos querido mostrar, a partir de documentación etnohistórica y etnográfica, que en el mundo de las almadrabas mediterráneas han persistido prácticas y percepciones que apuntalaban un sentido de la distribución, de reparto y de los derechos de propiedad que se ubicaban en los intersticios de regímenes de propiedad y racionalidades económicas híbridas. Podríamos resumir este código cultural en la reivindicación del derecho de apropiación sobre bienes que la naturaleza pone aleatoriamente a disposición de quien se esfuerza para apropiárselo. Para entender tales prácticas no es suficiente con acudir a lecturas utilitarias, como la necesidad de las economías domésticas para complementar las rentas -interpretación que ha de ser tenida en cuenta, pero que nos parece insuficiente. Se trata de la complementariedad de principios económicos que responden a lógicas diferentes, el utilitarismo frente a la reclamación de lo que se considera propio; la dimensión material, pero también la ideológica, axiológica, política y social, como hemos ido anotando con cada evidencia etnohistórica apuntada. El robo de pescado se corresponde con el principio de reciprocidad negativa tal como los define la antropóloga Paz Moreno, el reclamar lo que se considera justo (Moreno Feliú 2011). Hay una ilación en las situaciones que Hobsbawm (1983) identificó como rebeldía política, que Scott (2000) tildó de arte de resistencia, que Lomnitz calificó como reciprocidad negativa asimétrica o que Moreno Feliú (2002) asignó a la suspensión de un orden moral: el polo del reclamar se impone en las transacciones en juego en determinados marcos institucionales. Esa continuidad la podemos extender hacia la interpretación del texto marxiano sobre la leña seca y la lectura que hizo sobre él Bensaïd, al poner la lupa sobre «el hilo rojo que vincula el antiguo derecho consuetudinario a la "economía moral" de los pobres, a los derechos a la vida, a la existencia, al trabajo, a los ingresos, a la vivienda, derechos oponibles a los de la propiedad privada» (Bensaïd 2007: 115). Si bien las condiciones de existencia de los campesinos renanos no son comparables, en cuanto a vulnerabilidad, con las de los marineros almadraberos desde el siglo XX a la actualidad, sí lo es la existencia de un marco de moralidad que dota de sentido a esas prácticas.

Hay además una vertiente del problema que afecta de lleno a la evolución histórica de los modelos de propiedad; en particular, de qué modo, un conjunto de bienes pertenecientes al demanio público es políticamente apropiado por particulares. 
Si continuamos con la comparación entre el referente de los campesinos renanos y los almadraberos mediterráneos, «los derechos consuetudinarios de los pobres se basaban en que cierta propiedad tenía un carácter fluctuante que no hacía de ella con claridad una propiedad privada, pero tampoco con claridad una propiedad pública»; más bien se trata de «una mezcla de derecho privado y público», que más adelante refiere como "formas híbridas y fluctuantes de la propiedad» (Marx 2007: 37).

Como hemos querido argumentar a partir de Scott, Hobsbawm u Orlove, lo que el Derecho empezó a no reconocer, a partir de cierta bisagra histórica, seguía siendo reclamado por la población afectada mediante una táctica de resistencia, enmarcable en un modelo de reciprocidad negativa, que ha pretendido forzar las relaciones de poder instauradas, o al menos la mitigación de sus efectos, siendo el hurto, la apropiación de lo que el nuevo marco legal ya no permite, una de las más extendidas. Lo que diferencia al caso de los pescadores aquí analizados del caso de los campesinos andinos, por ejemplo (Gascón 1999-2000), es que entre los marineros los bienes siguen reclamándose como comunales, percepción que hemos interpretado en el marco de la vigencia de un modelo de reciprocidad negativa, en el sentido al que hacía referencia Moreno Feliú (2002 y 2011). Este modo reivindicativo también lo hemos podido documentar en un trabajo previo en otra práctica pesquera ejercida sobre un territorio costero que hasta los años ochenta del siglo XX había sido sometido a distintos regímenes de privatización: los corrales de pesca del litoral gaditano (Florido 2014a).

Por otro lado, hemos de tener en cuenta una dimensión de identificación social, históricamente enraizada: el almadrabero se define a sí mismo, en su cotidianidad, hurtando capturas accesorias. Existe una conciencia reflexiva sobre una práctica que se inscribe en una cultura laboral, que dota de identidad a sus detentadores, que prolonga su capacidad económica y otorga un sentido de cierta autonomía en sus estrategias. "Los almadraberos, como no roben un pescado..., tienen que robar pescado, lo tienen que robar» nos decía uno de los marineros de la almadraba de Zahara de los Atunes (Cádiz), necesidad no sentida, por ejemplo, cuando durante el invierno trabaja recogiendo aceitunas en Cataluña: "tengo a mano allí los litros de aceite, y no soy para robarlos». No es una necesidad entendible desde la subsistencia, sino desde el marco cultural apuntado, donde se amalgaman elementos de reivindicación justa, de competencia entre iguales ante el azar y de moralidad, en función del tipo de bien y de las relaciones que mantiene con él como sujeto histórico.

Hemos evidenciado, finalmente, que la modernización en la economía almadrabera había albergado modos culturales preexistentes que, incrustados, habían pervivido en las relaciones de producción capitalistas -una suerte de subsunción formal, por hacer uso del término marxiano-. Sin embargo, las transformaciones a las que está siendo sometida la economía almadrabera en el marco actual de ecología política constituyen la limitación efectiva de las prácticas analizadas -no de las percepciones y valores asociados-. Por tanto, parece que esa economía avanza ahora con paso firme hacia una subsunción real del trabajo, y de la naturaleza, en el capital (Sabbatella 2010), con la posibilidad de hacer desaparecer ese rico mundo de prácticas, relaciones y significados relacionados con el sentido de justicia, con la reivindicación política, o con el aprovechamiento comunalista de los bienes marinos.

\section{AGRADECIMIENTOS:}

Paz Moreno e Ignasi Terradas leyeron un borrador de este trabajo, aportando comentarios que ayudaron a perfilar determinados aspectos de las prácticas analizadas y de la interpretación teórica mantenida en el artículo.

\section{BIBLIOGRAFÍA CITADA}

Álvarez de Toledo, Luisa I. 2007. Las almadrabas de los Guzmanes. Sanlúcar de Barrameda (Cádiz): Fundación Casa Medina Sidonia.

Antón Solé, Pablo. 1965. Los Pícaros de Conil y Zahara. Estudio histórico sobre los jesuitas y las almadrabas del duque de Medina Sidonia en la segunda mitad del siglo XVI. Cádiz [s.n.].

Bensaïd, Daniel. 2007. «Marx y el robo de leña. Del derecho consuetudinario de los pobres al bien común de la humanidad». En Karl Marx, Los debates de la Dieta Renana: 95-125. Barcelona: Gedisa.

Caillois, Roger. 1997 [1967]. Los juegos y los hombres: La máscara y el vértigo. Bogotá: Fondo de Cultura Económica.

Cetti, Francesco. 1778. Anfibi e pesci della Sardegna. Sassari: Stamperia G. Piattoli. 
Conte, Giuseppe. 1985. Addio amico tonno. Indagine sulle tonnare di Portopaglia, Portoscuso e Isola Piana dal XVI secolo ai giorni nostri. Cagliari: Edizioni Della Torre.

Cote Montes, Eva. 2015. «Hombres del rebajale». Monográfico de la revista Cuadernos del Rebalaje, 30. Málaga: Amigos de la Barca de Jábega.

D’Amico, Francesco Carlo. 1816. Osservazioni pratiche intorno la pesca, corso e cammino de' tonni. Messina: Società Tipografica.

Di Lucia, Paolo. 2010. Normatividad. Derecho, lenguaje, acción. México: Fontanara.

Florido del Corral, David. 2002. Un siglo de historia e instituciones de la pesca en Andalucía. Sevilla: Junta de Andalucía y Fundación Blas Infante.

Florido del Corral, David. 2006. "Las almadrabas andaluzas: entre el prestigio y el mercado». En Genaro Chic (dir.). Economía de Prestigio Versus Economía de Mercado: 193214. Sevilla: Padilla.

Florido de Corral, David. 2013. "Las almadrabas andaluzas bajo el consorcio nacional almadrabero (1928-1971): aspectos socio-culturales y políticos». Sémata: Ciencias Sociais e Humanidades 25: 1-35.

Florido del Corral, David 2014a. "Los corrales de pesca en la provincia de Cádiz. Usos y apropiaciones en torno a un paisaje cultural». Periferias, Fronteras, Diálogos. Actas del XIII Congreso de Antropología de la Federación de Asociaciones de Antropología del Estado Español: 29352958. Tarragona: Universidad Rovira i Virgili.

Florido del Corral, David. 2014b. «La almadraba amenazada. Conflictos y paradojas socioambientales en la crisis del atún rojo». Periferias, Fronteras, Diálogos. Actas del XIII Congreso de Antropología de la Federación de Asociaciones de Antropología del Estado Español: 3325-3350. Tarragona: Universidad Rovira i Virgili y FAAEE.

Florido del Corral, David. 2017 (coord.). Las almadrabas suratlánticas andaluzas (siglos XVIII-XX). Historia, tradición, patrimonio. Sevilla: Editorial Universidad de Sevilla y Federación de Cofradías de Pescadores de la Provincia de Cádiz.

Gascón, Jorge. 1999-2000. «Robo y resistencia campesina en los Andes Peruanos». Quaderns de I'Institut Català d’Antropología 13-14: 163-171.

González Alcantud, José Antonio. 1993. Tractatus Ludorum. Una antropológica del juego. Barcelona: Paidós.

Gouldner, Alvin. 1960. "The Norm of Reciprocity: A Preliminary Statement». American Sociological Review 25: 161-178.

Graeber, David. 2012. En deuda. Una historia alternativa de la economía. Madrid: Ariel.

Gudeman, Stephen. 2001. The Anthropology of Economy. Oxford: Blackwell Publishers.

Guillaume-Alonso, Araceli. 1988. "Autour des confréries de marginaux: les almadrabas au siècle d'or». En Augustín Redondo (ed.), Les parentés fictives en Espagne (XVI-XVII siècles): 135-143. Paris: Publications de La Sorbonne.
Herrera Puga, Pedro. 1974. «La picaresca en el Estrecho de Gibraltar y el valle de S. Juan». En Pedro Herrera Puga, Sociedad y delincuencia en el Siglo de Oro: 337-350. Madrid: BAC.

Herrera Puga, Pedro. 1981. "Compendio del padre Pedro León. Parte primera: De las Misiones». En Pedro Herrera Puga, Grandeza y miseria en Andalucía. Testimonio de una encrucijada (1578-1616): 65-80. Granada: Biblioteca Teológica Granadina.

Hobsbawm, Eric. 1978. «Bandolerismo social». En Henry Adolf Landsberger (ed.), Rebelión campesina y cambio social: 192213. Barcelona: Crítica.

Hobsbawm, Eric. 1983. Rebeldes Primitivos. Barcelona: Ariel.

Horozco, Agustín de. 2001. Historia de la ciudad de Cádiz. Cádiz: Servicio de publicaciones de la Universidad de Cádiz.

Lentini, Rosario. 1986. "Economia e storia delle tonnare di Sicilia». En Consolo V., La pesca del tonno in Sicilia: 31-56. Palermo: Sellerio.

Lomnitz, Caludio. 2005. "Sobre reciprocidad negativa». Revista de Antropología Social 14: 311-339.

Marx, Karl. 2007. Los debates de la Dieta Renana. Barcelona: Gedisa.

Moreno Feliú, Paz. 2002. «Organizar: suspensión de la moralidad y reciprocidad negativa». Endoxa 15: 97-118.

Moreno Feliú, Paz. 2011. El bosque de las gracias. Madrid: Trotta.

Orlove, Benjamín. S. 1990. "La posición de los abigeos en la sociedad regional (El bandolerismo social en el Cusco en vísperas de la reforma agraria)». En Aguirre, Carlos y Charles Walker (eds.), Bandoleros, abigeos y montoneros: 277-305. Lima: Instituto de Apoyo Agrario.

Palenzuela, Pablo. 1995. "Las culturas del trabajo: una aproximación antropológica». Sociología del Trabajo 24: 3-24.

Pavesi, Pietro. 1889. L'industria del tonno: relazione alla Commissione Reale per le tonnare. Roma: Eredi Botta.

Rajchenberg, Enrique. 2015. «De la rebelión a la resistencia: De Eric Hobsbawm a James C. Scott». Bajo el Volcán 15 (22): 41-59.

Ravazza, Ninni. 2005. Diario di tonnara. Milano: Magenes.

Ravazza, Ninni. 2007. Il sale e il sangue. Storie di uomini e tonni. Milano: Magenes.

Ríos Jiménez, Segundo. 2005. «Evolución de la gran empresa almadrabero-conservera andaluza entre 1919 y 1936: génesis y primeros pasos del Consorcio Nacional Almadrabero». Comunicación presentada al VIII Congreso de la Asociación de Historia Económica.

Rubino, Salvatore. 1994. La tonnara Saline. Alghero: La Celebre Edetrice.

Sabbatella, Ignacio. 2010. "Crisis ecológica y subsunción real de la naturaleza al capital». Iconos. Revista de Ciencias Sociales 36: 69-80.

Sahlins, Marshall. 1963. "On the Sociology of Primite Exchange». En Max Gluckman y Fred Eggan (eds.), The 
Relevance of Models for Social Anthropology: 139-236. New York: F. Praeger.

Santos, Antonio. 2017. «Historia social y conformación de las culturas del trabajo y organización empresarial entre los siglos XVIII y XIX». En Florido, David (coord.), Las almadrabas suratlánticas andaluzas (siglos XVIII-XX). Historia, tradición, patrimonio: 29-74. Sevilla: Editorial Universidad de Sevilla.

Sáñez Reguart, Antonio. 1791. Diccionario histórico de los artes de la pesca nacional. Cinco Volúmenes. Madrid: Viuda de Joaquín Ibarra.

Sarà, Raimondo. 1998. Dal mito all'aliscafo. Storie di tonni e tonnare. Palermo: Arti Grafiche Siciliane.

Scott, James C. 1999. Elementary Aspects of Peasant Insurgency in Colonial India. Durham-London: Duke University Press

Scott, James C. 2000. Los dominados y el arte de la resistencia. México: Era.

Scott, James C. 2013. Decoding Subaltern Politics. Ideology, Disguise and Resistance in Agrarian Politics. Oxon/New York: Routledge.
Soto Melgar, Mercedes. 2015. Terminología marinera gaditana. Estudio lingüístico-etnográfico. Tesis doctoral. Universidad de Granada.

Terradas Saborit, Ignasi. 2008. Justicia Vindicatoria. Madrid: Consejo Superior de Investigaciones Científicas.

Thomas, Nicholas. 1991. Entangled Objects: Exchange, Material Culture and Colonialism in the Pacific. Cambridge: Harvard University Press.

Thompson, Edward. P. 1975. Whigs and Hunters: The Origin of the Black Act. New York: Pantheon Books.

Villabianca, Francesco Maria Emanuele e Gaetani, 1986 [1774]. Le tonnare della Sicilia (Opuscoli del Marchese di Villabianca). Palermo: Giada.

Weiner, Anette. 1996. «Reciprocity». En David Levinson y Melvin Ember (comps.), Encyclopedia of Cultural Anthropology: 1060-1068. New York: H. Holt.

Zambernardi, Ambra 2020. Calar tonnara. tnografia di una maricultura mediterranea. Tesis doctoral. Universidad de Torino y Universidad de Sevilla. 